\title{
Simulation and Experimental Analysis of a Brushless Electrically-Excited Synchronous Machine with a Hybrid Rotor
}

\author{
Fengge Zhang, Guanglong Jia, Yunwu Zhao, Zheng Yang, Wenping Cao, Senior Member, IEEE, James \\ L. Kirtley, Jr., Life Fellow, IEEE
}

\begin{abstract}
Electrically excited synchronous machines with brushes and slip rings are popular but hardly used in inflammable and explosive environments. This paper proposes a new brushless electrically-excited synchronous motor (BEESM) with a hybrid rotor. It eliminates the use of brushes and sliprings so as to improve the reliability and cost-effectiveness of the traction drive. The proposed motor is characterized with two sets of stator windings with two different pole numbers to provide excitation and drive torque independently. The paper introduces the structure and operating principle of the machine, followed by the analysis of the air-gap magnetic field using the finite element method (FEM). The influence of the excitation winding's pole number on the coupling capability is studied and the operating characteristics of the machine are simulated. These are further examined by experimental tests on a $16 \mathrm{~kW}$ prototype motor. The machine is proved to have good static and dynamic performance which meets the stringent requirements for traction applications.
\end{abstract}

Index Terms - Brushless excitation, finite element method, hybrid rotor, magnetic field modulation, synchronous machines.

\section{INTRODUCTION}

E LECTRICAL machines are the core equipment of electricity generation systems and industrial drives. Due to speed stability and controllability of power factor, synchronous machines have been widely used in energy and power industry.

In the literature, many synchronous machines utilize expensive rare-earth-based permanent magnets (PMs). Currently, permanent magnet synchronous motors (PMSMs) dominate the low-power and high-end market because of their high power density and high efficiency [1]-[3]. However, the costs of PMs (e.g. $\mathrm{NdFeB}$ ) are high giving rise to the system cost and environmental issues in the extraction of rare-earth materials. More importantly, their known reserve cannot sustain any mass-production markets such as automobiles or wind turbines. Some new machines are developed to use ferrite magnets while other eliminate the use of magnets (e.g.

This work was jointly supported by the National Science Foundation of China (51277125), the Specialized Research Fund for the Doctoral Program of Higher Education (20122102110004) and the Seventh Framework Programme of the European Union projects (318925 and 627270).

F. Zhang, G. Jia, Y. Zhao, Y. Zheng are with the School of Electrical Engineering, Shenyang University of Technology, 110870, China (zhangfg@sut.edu.cn).

W. Cao and J. Kirtley are with the Department of Electrical Engineering and Computer Science, Massachusetts Institute of Technology, Cambridge, MA 02139, U.S.A. reluctance machines). Among these, brushless doubly-fed machines (BDFMs) eliminate the use of magnets and brushes so as to reduce the capital cost and converter rating. Typical BDFMs have a single stator that houses two sets of 3-phase windings with two different pole numbers [4]-[7], and a wound or reluctance rotor.

Similarly, electrically-excited synchronous machines have attracted much attention in eliminating PMs. But they still rely on brushes and sliprings to access the rotor circuits, which can increase maintenance costs and safety hazards. Even though some machines employ rotating rectifiers to eliminate brushes and sliprings, these rectifiers and exciters can increase the axial length of the machine.

This paper proposes a new brushless electrically-excited synchronous motor (BEESM) which removes the brushes and sliprings for traction drives used in inflammable and explosive environments. The motor is featured with a hybrid rotor and two sets of stator windings (the armature winding and the excitation winding) with two different pole numbers. The machine is thus improved over traditional ones in terms of reliability and cost efficiency.

\section{OPERATING PRINCIPLE AND MAGNETIC FIELD MODULATION MECHANISM}

\section{A. Operating Principle}

When the BEESM operates in a steady state, its armature winding is directly connected to an AC supply and its excitation winding to a DC excitation controller, as shown in Fig. 1. There are two magnetic fields in the air gap. One is the rotating magnetic field generated by the armature winding supplied by $\mathrm{AC}$ power and the other is a constant magnetic field produced by the excitation winding supplied by DC power. The hybrid rotor modulates the two magnetic fields and acts as a magnetic barrier and the cage rotor [8]-[12]. Their relationships are:

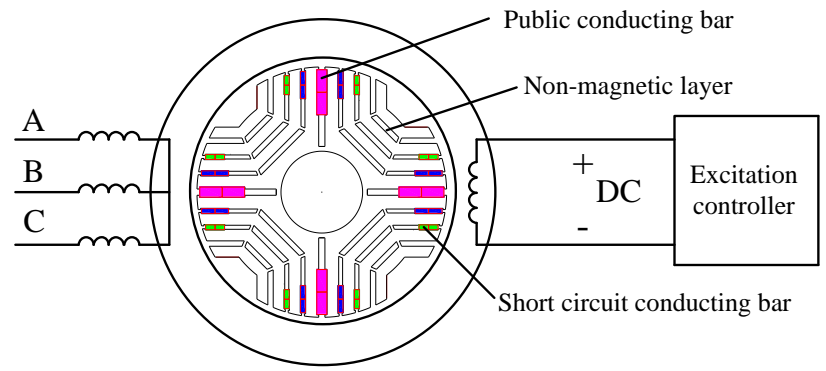

Fig. 1 Schematic of the proposed BEESM. 
IEEE Transactions on Magnetics

$$
\begin{aligned}
& p_{r}=p_{p}+p_{f} \\
& \mathrm{n}_{r}=\frac{60 f}{p_{p}+p_{f}}
\end{aligned}
$$

where $p_{r}, p_{p}$ and $p_{f}$ are the number of pole pairs of the rotor, armature winding and excitation winding, respectively. $n_{\mathrm{r}}$ is the synchronous speed in rpm and $f$ is the supply frequency in $\mathrm{Hz}$.

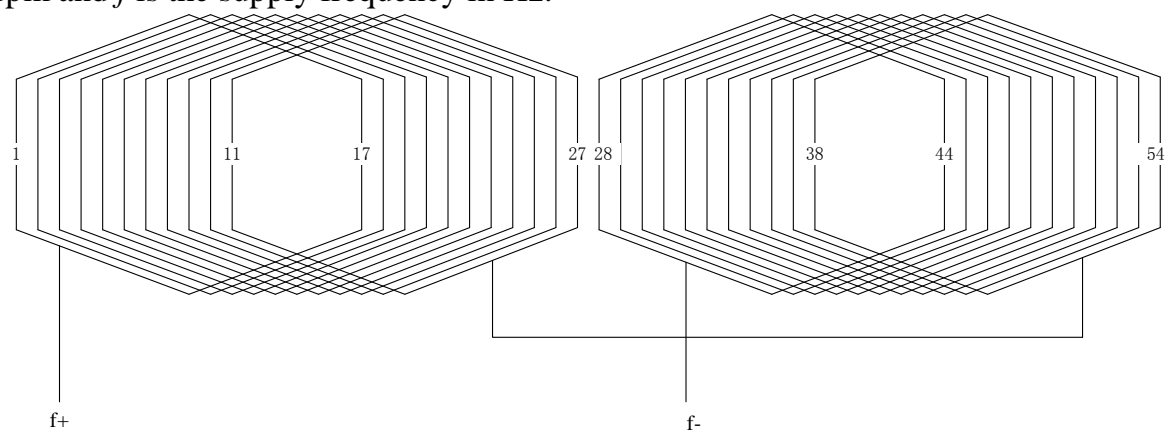

Fig. 2 Excitation winding topology.

The excitation winding is initially connected to a single-phase supply with a starter resistance. By adjusting this resistance, the starting characteristics of the BEESM can be regulated. When the speed increases to near the synchronous speed, the excitation winding is quickly switched to a DC supply. Then the BEESM is pulled into synchronism. By controlling the current in the excitation winding, the reactive component of the armature current can be adjusted.

\section{B. Magnetic Field Modulation}

The air-gap permeance of the hybrid rotor is shown in Fig. 3. When the rotor is operational, the air-gap permeance relative to the stator can be expressed as:

$$
\lambda_{g}(\varphi, t)=\lambda_{0}+\lambda_{1} \cos \left[p_{r}\left(\varphi-\theta_{r 0}-\omega_{r m} t\right)\right]
$$

where $\lambda_{0}$ is the average air-gap permeance, $\lambda_{1}$ is the amplitude of the fundamental permeance, $\theta_{\mathrm{r} 0}$ is the angle between the rotor reference axis and the armature magnetomotive force (mmf), and $\omega_{\mathrm{rm}}$ is the angular speed of the rotor.

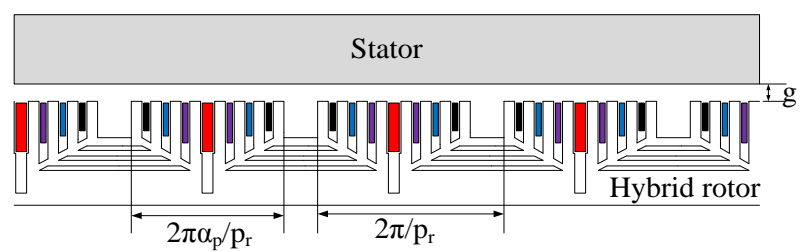

(a) Expanded view of the hybrid rotor

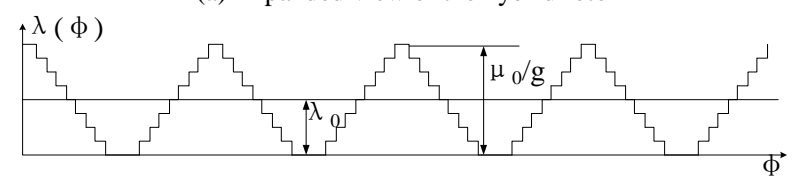

(b) Air-gap permeance

Fig. 3 Air-gap permeance of the proposed motor.

Both the armature winding and excitation winding can set up a rotating $\mathrm{mmf}$.

$$
\begin{gathered}
f_{p}(\varphi, t)=F_{p} \cos \left(p_{p} \varphi-\omega_{p} t\right) \\
f_{f}(\varphi)=F_{f} \cos \left(p_{f} \varphi-\alpha\right)
\end{gathered}
$$

where $\varphi$ is the position angle relative to the stator reference, $\alpha$ is
The armature winding is a three-phase short-pitch winding and is placed at the top layer of the double-layer stator slots. The pitch of armature winding is 7 . The excitation winding situates at the bottom of stator slots and its winding topology is shown in Fig. 2. The pitch of excitation winding is 16 . the angle between the two mmfs produced by the armature winding and excitation winding. $\omega_{\mathrm{p}}$ is the angular frequency of the armature current.

The total mmf is the sum of the two mmfs. So the air-gap magnetic flux density can be expressed as

$$
B(\varphi, t)=\left[f_{p}(\varphi, t)+f_{f}(\varphi)\right] \lambda_{g}(\varphi, t)
$$

Substituting (3)-(5) into (6),

$$
\begin{gathered}
B(\varphi, t)=\left[F_{p} \cos \left(p_{p} \varphi-\omega_{p} t\right)+F_{f} \cos \left(p_{f} \varphi-\alpha\right)\right] . \\
{\left[\lambda_{0}+\lambda_{1} \cos \left[p_{r}\left(\varphi-\theta_{r 0}-\omega_{r m} t\right)\right]\right]} \\
=B_{p 0}+B_{f 0}+B_{p 1(+)}+B_{p 1(-)}+B_{f 1(+)}+B_{f 1(-)} \\
\text { where } \begin{array}{c}
B_{p 0}=F_{p} \lambda_{0} \cos \left(p_{p} \varphi-\omega_{p} t\right) \\
B_{f 0}=F_{f} \lambda_{0} \cos \left(p_{f} \varphi-\alpha\right)
\end{array} \\
B_{p 1(+)}=F_{p}\left(\lambda_{1} / 2\right) \cos \left[\left(p_{p}+p_{r}\right) \varphi-\left(\omega_{p}+p_{r} \omega_{r m}\right) t-p_{r} \theta_{r 0}\right] \\
B_{p 1(-)}=F_{p}\left(\lambda_{1} / 2\right) \cos \left[\left(p_{p}-p_{r}\right) \varphi-\left(\omega_{p}-p_{r} \omega_{r m}\right) t+p_{r} \theta_{r 0}\right] \\
B_{f 1(+)}=F_{f}\left(\lambda_{1} / 2\right) \cos \left[\left(p_{f}+p_{r}\right) \varphi-p_{r} \omega_{r m} t-\alpha-p_{r} \theta_{r 0}\right] \\
B_{f 1(-)}=F_{f}\left(\lambda_{1} / 2\right) \cos \left[\left(p_{f}-p_{r}\right) \varphi+p_{r} \omega_{r m} t-\alpha+p_{r} \theta_{r 0}\right]
\end{gathered}
$$

From (1), the speed of the motor is derived by

$$
\omega_{r m}=\frac{\omega_{p}}{p_{r}}=\frac{\omega_{p}}{p_{p}+p_{f}}
$$

Substituting (14) into (11)-(13), the airgap flux density is found.

$$
\begin{gathered}
B_{p 1(-)}=F_{p}\left(\lambda_{1} / 2\right) \cos \left[p_{f} \varphi-p_{r} \theta_{r 0}\right] \\
B_{f 1(+)}=F_{f}\left(\lambda_{1} / 2\right) \cos \left[\left(2 p_{f}+p_{p}\right) \varphi-\omega_{p} t-\alpha-p_{r} \theta_{r 0}\right] \\
B_{f 1(-)}=F_{f}\left(\lambda_{1} / 2\right) \cos \left[p_{p} \varphi-\omega_{p} t+\alpha-p_{r} \theta_{r 0}\right]
\end{gathered}
$$

These three parameters are key indicators of machine magnetic performance.

\section{INFLUENCE OF THE POLE NUMBER OF THE EXCITING WINDING'S ON THE COUPLING CAPACITY}

The pole number is an important factor for the coupling capability. If one set of the stator winding is excited, the other set of stator winding is induced. The order of induced harmonic components is the integral number of the poles.

In order to evaluate the influence of the excitation winding's 
pole number on the machine performance, a BEESM with $6 / 2$ poles is first modeled and analyzed. A spectrum diagram of the air-gap flux density with different excitation schemes is shown in Fig. 4. From Fig. 4(a), it can be seen that, when the 6 poles are excited, the motor produces a greater fundamental harmonic and the greatest $3^{\text {rd }}$ harmonic. From Fig. 4(b), when the 2 poles are excited, the motor produces a greater fundamental harmonic and also the greatest $3^{\text {rd }}$ harmonic. In addition, its $5^{\text {th }}, 7^{\text {th }}, 13^{\text {th }}$ and $17^{\text {th }}$ components are all greater than these in Fig. 4(a).

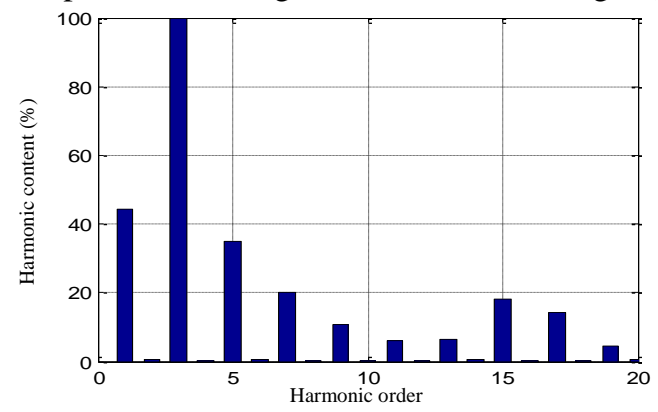

(a) 2-pole armature,6-pole excitation

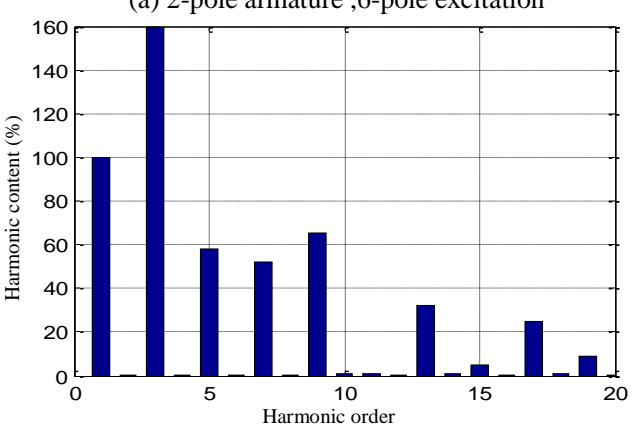

(b) 6-pole armature, 2-pole excitation

Fig. 4 Spectral analysis of the air-gap flux density with the $6 / 2$ poles.

\section{Simulation OF THE Machine CHARACTERISTICS}

The starting of the BEESM is easier than conventional PMSMs since it can be started as an induction motor without the aid of auxiliary equipment. The parameters of the BEESM are listed in Table I and the motor is modeled by the finite element method (FEM) in Ansoft.

\section{TABLE I MAIN PARAMETERS OF THE MACHINE}

\begin{tabular}{|c|c|}
\hline Item & Value \\
\hline Power & $16 \mathrm{~kW}$ \\
\hline Supply winding frequency & $50 \mathrm{~Hz}$ \\
\hline Synchronous speed & $750 \mathrm{rpm}$ \\
\hline Pole number of the armature winding & 6 \\
\hline Pole number of the excitation winding & 2 \\
\hline Stack length & $240 \mathrm{~mm}$ \\
\hline Number of stator slots & 54 \\
\hline Stator outer diameter & $400 \mathrm{~mm}$ \\
\hline Stator inner diameter & $260 \mathrm{~mm}$ \\
\hline Airgap length & $0.8 \mathrm{~mm}$ \\
\hline Rotor outer diameter & $258.4 \mathrm{~mm}$ \\
\hline Rotor inner diameter & $85 \mathrm{~mm}$ \\
\hline Rotor moment of inertia & $0.776 \mathrm{~kg} \cdot \mathrm{m}^{2}$ \\
\hline Armature winding resistance & $0.1612 \Omega$ \\
\hline Excitation winding resistance & $0.6641 \Omega$ \\
\hline d-axis inductance & $0.022123 \mathrm{H}$ \\
\hline q-axis inductance & $0.020014 \mathrm{H}$ \\
\hline
\end{tabular}

The magnetic field distribution and flux line distribution from both armature and field windings are obtained and shown in Fig. 5.

When the BEESM operates in the steady state, its radial flux density and tangential flux density in the air-gap are obtained and the results are presented in Fig. 6. These results show that the motor has good electromagnetic performance.

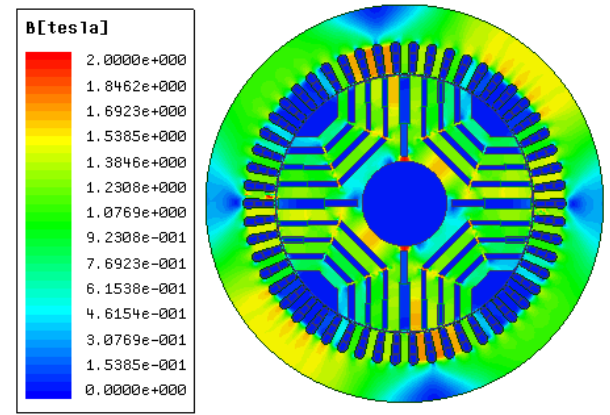

(a) Magnetic field distribution.

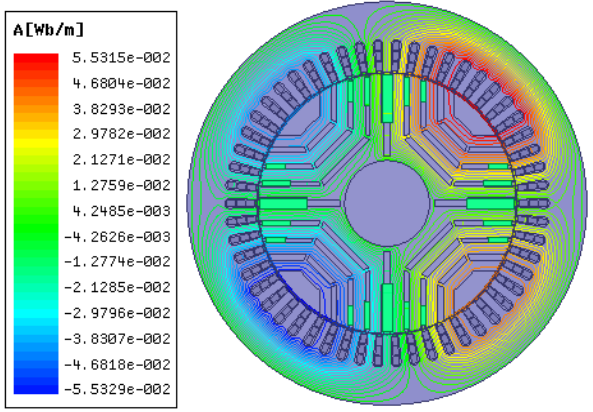

(b) Flux line distribution

Fig. 5 Magnetic field distribution and flux distribution in the machine.

The calculated self- and mutual inductances are shown in Fig. 7. $L_{\mathrm{AA}}$ is the self-inductance of phase A armature winding and $L_{\mathrm{AB}}$ is the mutual inductance between phases $\mathrm{A}$ and B. $L_{\mathrm{Af}}$ is the mutual inductance between phases $A$ and $\mathrm{f}$. It can be seen from Fig. 7(b) that the mutual inductance is a function of rotor physical position.

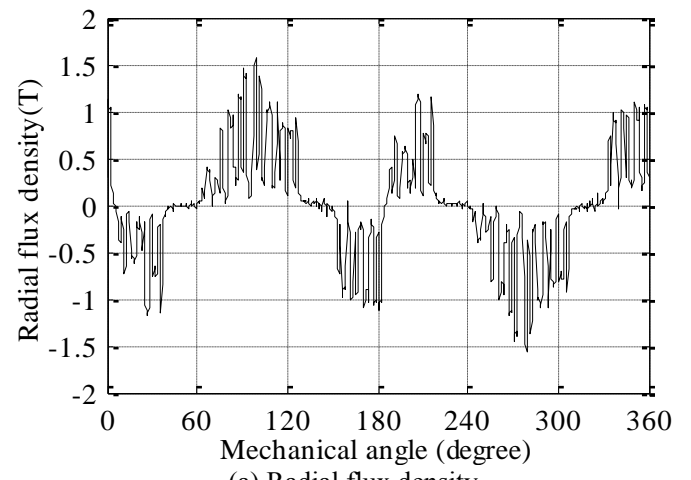

(a) Radial flux density 


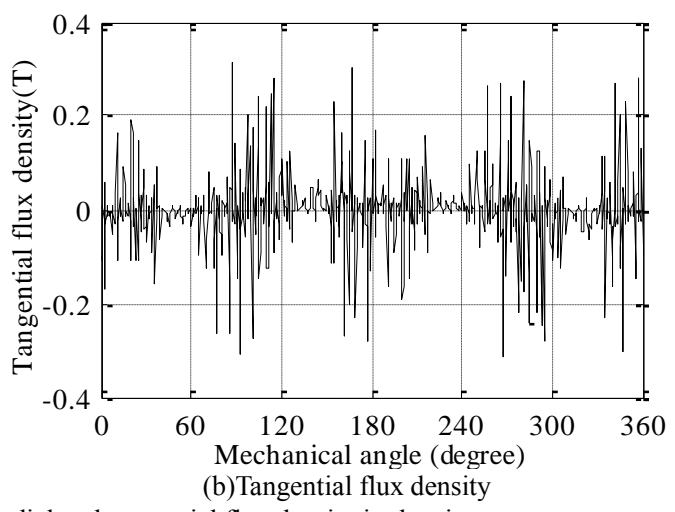

Fig. 6 Radial and tangential flux density in the airgap.

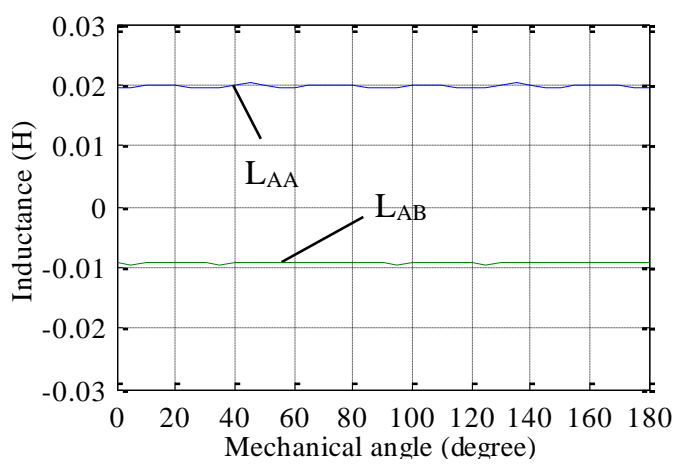

(a) Inductances of the armature winding

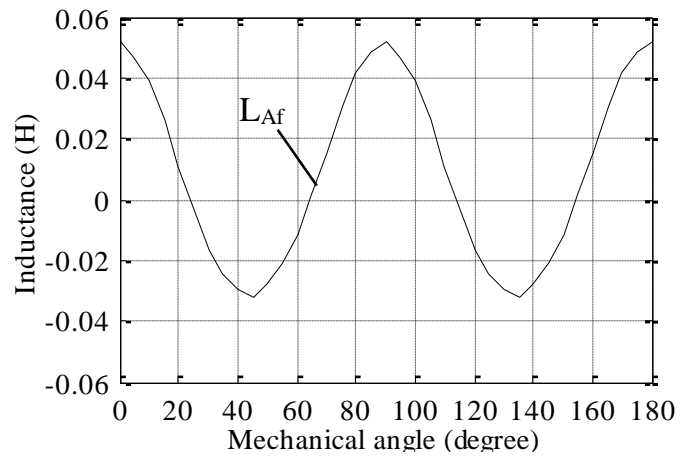

(b) Mutual inductance between armature winding and excitation winding Fig. 7 The self- and mutual inductances of BEESM.

Next, the motor's speed response is studied. Initially, the motor speed increases and reaches its rated speed within $0.5 \mathrm{~s}$. At $0.8 \mathrm{~s}$, the excitation winding is supplied by the excitation controller to stabilize the motor. The speed of the BEESM shows a slight change, as in Fig. 8. When the load increases to $30 \mathrm{Nm}$ at $1.7 \mathrm{~s}$, the motor speed fluctuates slightly around 750 rpm over the period of 1.7-2.2s, as shown in Fig. 8. After a short period of the disturbance, the machine returns back to the synchronous operation.

Also at $0.8 \mathrm{~s}$ when the exciting winding is supplied by the DC source, the armature current is decreased, as shown in Fig. 9. This is because that the excitation current adjusts the reactive power of the motor. At $1.7 \mathrm{~s}$ when the motor load is increased to $30 \mathrm{Nm}$, the armature current increases and so do the electromagnetic torque and the speed. The electromagnetic torque is shown in Fig. 10. Within 0.3s, the machine can again operate at synchronous speed. These results demonstrate a good dynamic response of the BEESM.

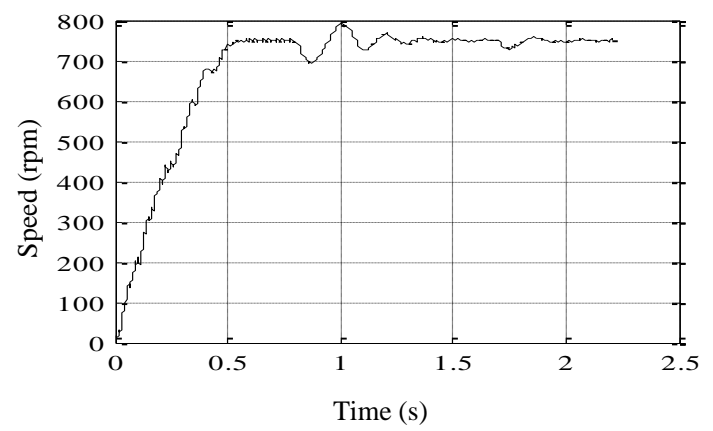

Fig. 8 Speed response to a sudden load change.

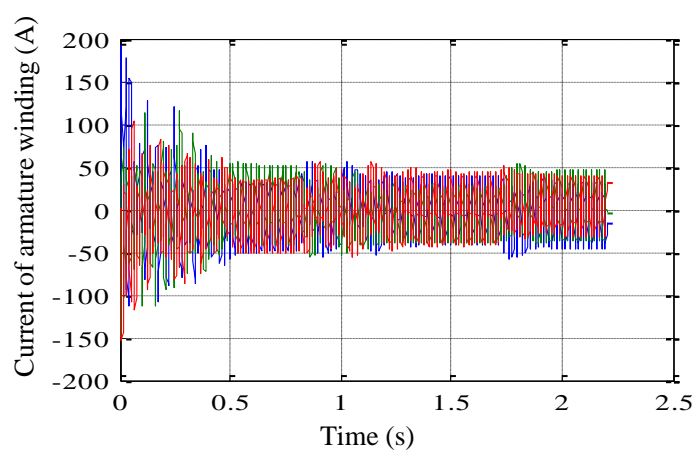

(a) Armature winding current

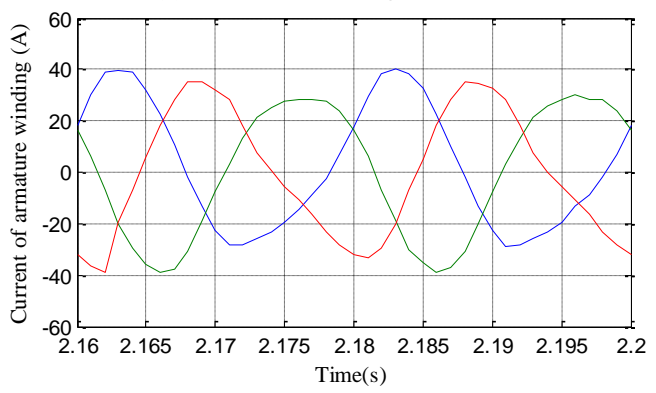

(b) Local current

Fig. 9 Fluctuation of the armature winding current and load current.

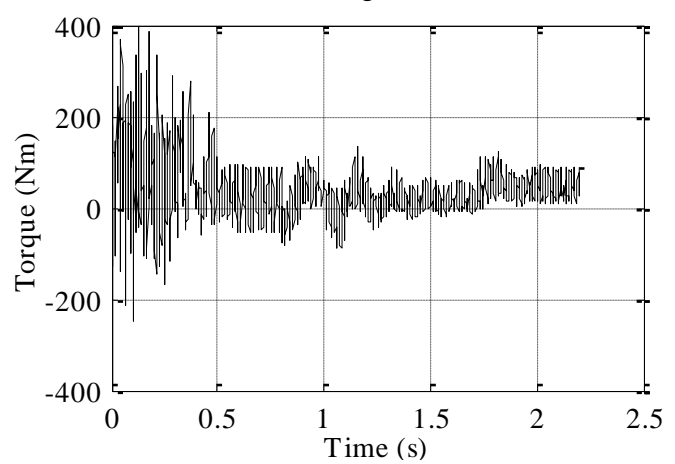

Fig. 10 Fluctuation of the torque.

\section{EXPERIMENTAL VALIDATION}

Following the numerical study, the motor is prototyped and experimentally tested to validate the design. Figs. 11 and 12 show photographs of the rotor and the experimental setup, respectively. An eddy-current dynamometer is used as the mechanical load. The prototype machine is equiped with a torque transducer and a speed sensor to measure the load torque and speed. Test results are read from a high-precision three-phase power analyzer. 


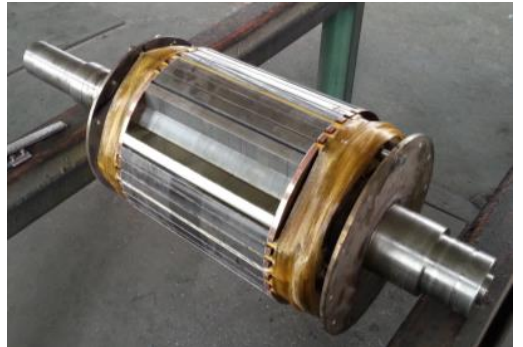

Fig. 11 The hybrid rotor of the prototype motor.

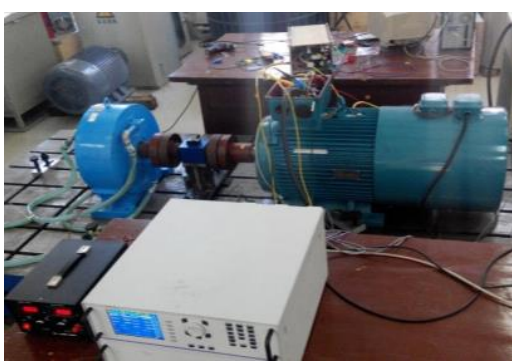

Fig. 12 Experimental setup.

The inductances of the BEESM are measured by the static test method. The armature winding of a phase is fed by a $50 \mathrm{~V}$ $50 \mathrm{~Hz}$ supply and other windings are open-circuited. The measured self- and mutual inductances are shown in Fig. 13. Table II presents a comparison of calculated and measured inductances. It can be seen that the measured $L_{\mathrm{AA}}$ and $L_{\mathrm{AB}}$ are slightly higher than simulated values and the measured $L_{A f}$ is slightly lower than simulated value. Overall the measured inductances agree well with and the calculated results. Since the coupling capability of the BEESM can be represented by the ratio of $L_{\mathrm{Af}}$ to $L_{\mathrm{AA}}$. The greater the ratio, the stronger the coupling capability. The calculated ratio is higher than the measured one, owing to an ideal condition used in simulation.

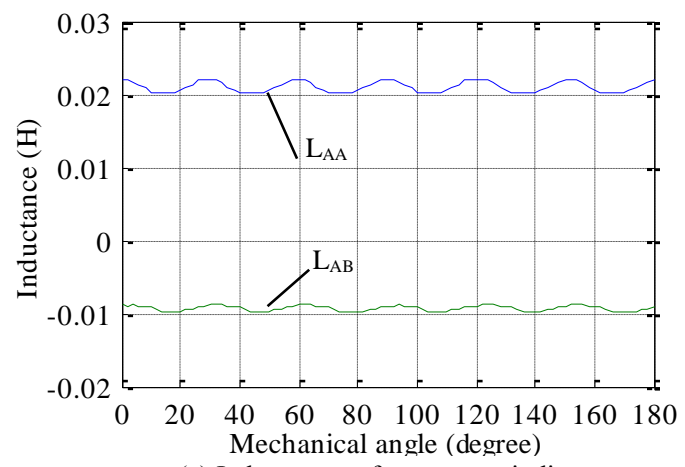

(a) Inductances of armature winding

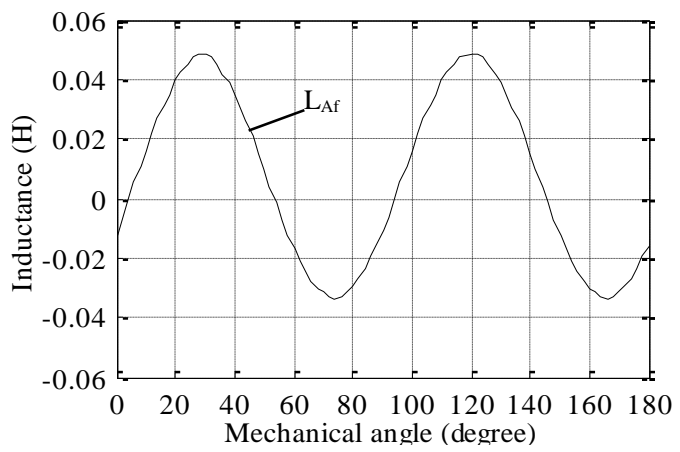

(b) Mutual inductance between armature winding and excitation winding Fig. 13 Inductance measurements of the prototype machine.
TABLE II MEASURED AND SIMULATED INDUCTANCES

\begin{tabular}{|l|c|c|}
\hline \multicolumn{1}{|c|}{ Item } & $\begin{array}{c}\text { Calculated inductance } \\
(\mathbf{H})\end{array}$ & $\begin{array}{c}\text { Measured inductance } \\
(\mathbf{H})\end{array}$ \\
\hline $\mathrm{L}_{\mathrm{AA}}$ & 0.0197 & 0.021 \\
\hline $\mathrm{L}_{\mathrm{AB}}$ & 0.0093 & 0.095 \\
\hline $\mathrm{L}_{\mathrm{Af}}$ & 0.0522 & 0.0485 \\
\hline $\mathrm{L}_{\mathrm{Af}} / \mathrm{L}_{\mathrm{AA}}$ & 2.65 & 2.31 \\
\hline
\end{tabular}

Next, the armature winding is fed by a $330 \mathrm{~V} 50 \mathrm{~Hz}$ supply and the excitation winding is connected with a $13 \Omega$ resistance. The process of machine starting, pulling into synchronism and a sudden load (at $23 \mathrm{~s}$ ) are recorded by the torque transducer, speed sensor and power analyzer. The results are shown in Figs. 14, 15, and 16. As can be seen from these, experimental results are similar to simulated results. When the load is increased from 0 to $30 \mathrm{Nm}$, there is little fluctuation in speed.

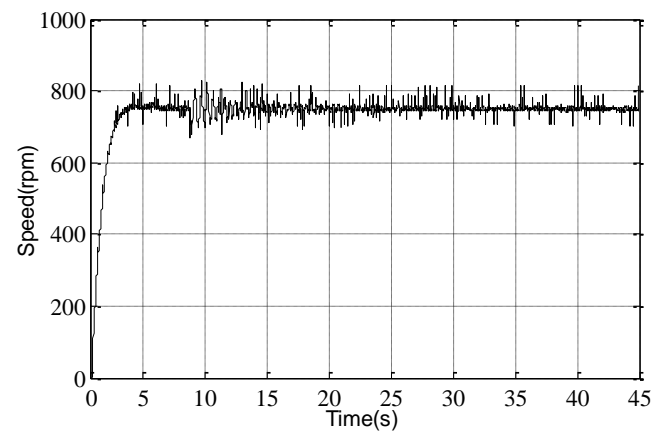

Fig. 14 Speed change from starting up.

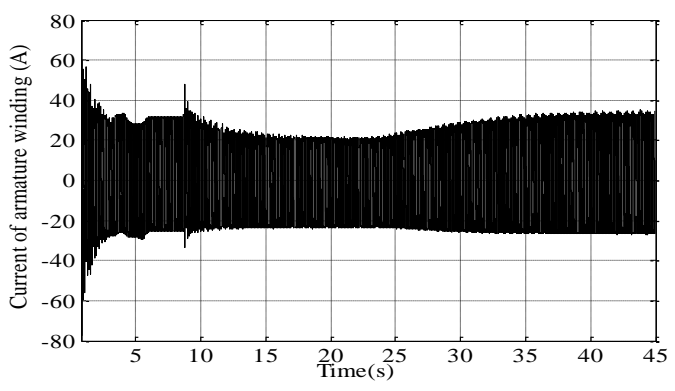

(a) Armature winding current

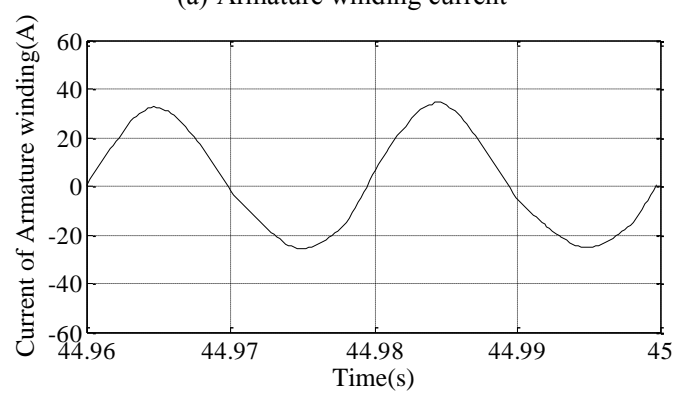

(b) Local current

Fig. 15 Current changes.

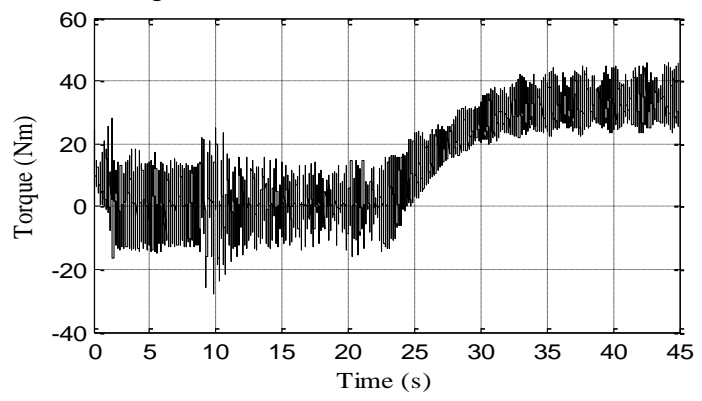

Fig. 16 Torque change. 
When the prototype machine is operated under no-load and a 3-kW load conditions, the excitation current increases gradually. The curves of the armature current against the exciting current are obtained and shown in Fig. 17. At first the armature current decreases with the rising excitation current. When the excitation current value increases to a certain threshold (32A), the armature current starts to increase with the excitation current. For a given output power, the reactive power can be regulated by varying the excitation current.

Clearly, the power factor and power angle also change with the excitation current. When the power factor is maximum, the armature current is minimum. For example, when the BEESM operates without load, the excitation winding is supplied with 9A and $41 \mathrm{~A}$ direct current. The curve of the armature voltage and current are shown in Fig. 18. When excitation current is $9 \mathrm{~A}$, the armature current lags behind the armature voltage. i.e. lagging power factor. This is inverse when the excitation current is $41 \mathrm{~A}$ (over-excitation).

Then the excitation winding is supplied with the rated DC voltage, the mechanical load is gradually increased from zero to rated value while maintaining the excitation current. The output power, machine efficiency and power factor are attained, as plotted in Fig. 19. It can be seen that, as the load increases, the machine efficiency and power factor increase rapidly and thereafter increase a little to the peak values, and then decrease slightly. The power factor peaks at around $70 \%$ load while the maximum efficiency is $83.5 \%$ at the $85 \%$ load.

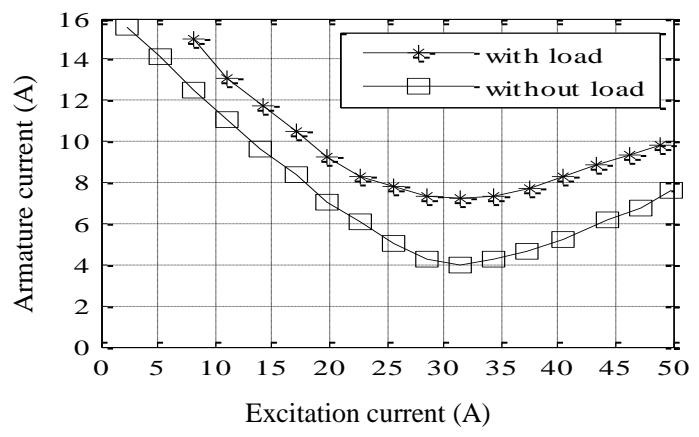

Fig. 17 Curves of the armature current against the exciting current.

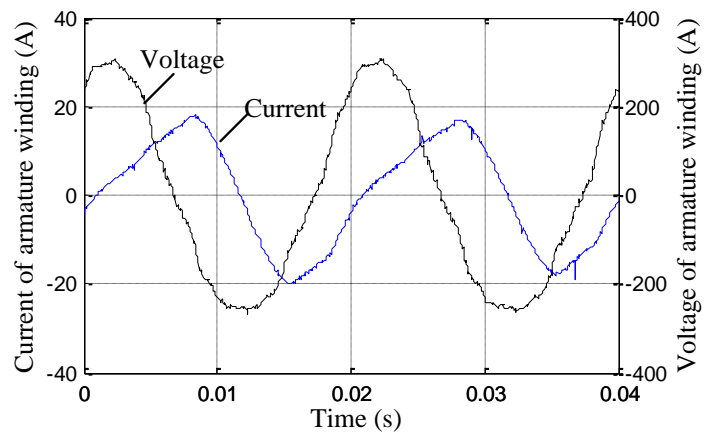

(a) Excitation current 9A

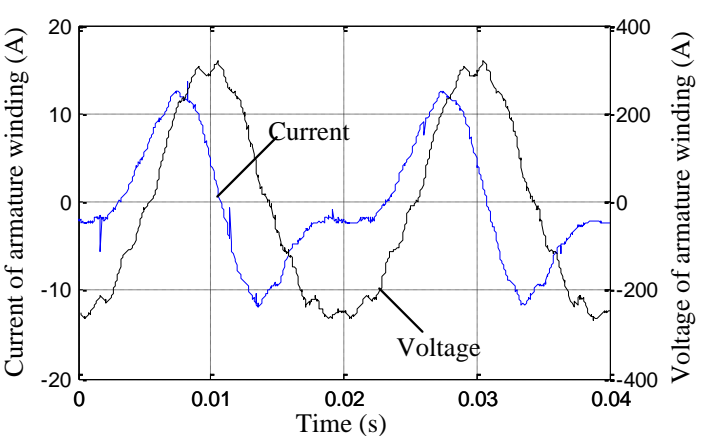

(b) Excitation current $41 \mathrm{~A}$

Fig. 18 Armature voltage and current.

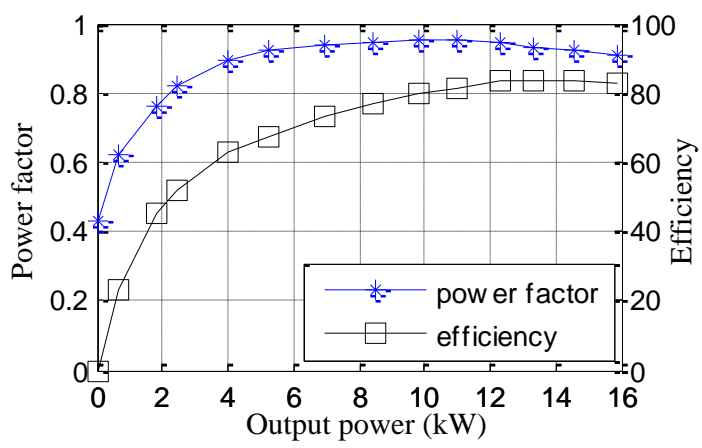

Fig. 19 Curves of the power factor and machine efficiency.

\section{CONCLUSION}

This paper has presented a new BEESM for traction drive applications. The structures of stator windings and rotor are described. Based on numerical analysis of the air-gap flux and its permeance function, the operational principle and electromechanical energy conversion of this motor have been revealed. A $6 / 2$ pole combination is chosen for the BEESM. A machine prototype has been manufactured. Numerical and experimental results agree well and have shown that the static and dynamic characteristics of the proposed motor are satisfactory. The developed motor can be used for traction drives in hazardous environments.

\section{REFERENCES}

[1] G. Pellegrino, A. Vagati, P. Guglielmi, and B. Boazzo, "Performance comparison between surface-mounted and interior PM motor drives for electric vehicle application," IEEE Trans. Ind. Electron., vol. 59, no. 2, pp. 803-811, Feb. 2012.

[2] K. T. Chau, C. C. Chan, and C. Liu, "Overview of permanent-magnet brushless drives for electric and hybrid electric vehicles," IEEE Trans. Ind. Electron., vol. 55, no. 6, pp. 2246-2257, Jun. 2008.

[3] K. C. Kim, "A novel calculation method on the current information of vector inverter for interior permanent magnet synchronous motor for electric vehicle," IEEE Trans. Mag., vol. 50, no.2, pp. 829-832, Feb. 2014.

[4] Huijuan Liu, Longya Xu. "Performance Analysis of Doubly Excited Brushless Machine with Radially Laminated Magnetic Barrier Rotor," Advanced Materials Research. 2012, 383: 1837-1843.

[5] D. G. Dorrell, A. M. Knight, R. E. Betz, "Improvements in brushless doubly fed reluctance generators using high-flux-density steels and selection of the correct pole numbers," IEEE Trans. Magnetics, vol. 47, no. 10, pp. 4092-4095, Oct. 2011.

[6] M. G. Jovanovic, R. E. Betz, J. Yu, "The use of doubly fed reluctance machines for large pumps and wind turbines," IEEE Trans. Industry Applications, vol. 38, no. 6, pp. 1508-1516, Nov./Dec. 2002. 


\section{IEEE Transactions on Magnetics}

[7] D. G. Dorrell, A. M. Knight, W. K. Song and R. E. Betz. "Saturation and ducting effects in a brushless doubly-fed reluctance machine," IEEE Trans. Magnetics, vol. 49, no. 7, pp. 3933-3936, Jul. 2013.

[8] M. F. Hsieh, I. H. Lin and D. G. Dorrell, "Magnetic circuit modeling of brushless doubly-fed machines with induction and reluctance rotors," IEEE Trans. Magnetics, vol. 49, no. 5, 2359-2362, May 2013.

[9] R. E. Betz and M. G. Jovanovic, "The brushless doubly fed reluctance machine and the synchronous reluctance machine-A comparison," IEEE Trans. Ind. Appl., vol. 36, no. 4, pp. 1103-1110, Jul./Aug. 2000.

[10] R. A. McMahon, P. C. Roberts, X. Wang, and P. J. Tavner, "Performance of BDFM as generator and motor," Proc. Inst. Elect. Eng.-Elect. Power Appl., vol. 153, no. 2, pp. 289-299, Mar. 2006.

[11] A. M. Knight, R. E. Betz and D. G. Dorrell, "Design principles for brushless doubly fed reluctance machines," IEEE Trans. Ind. Appl., vol. 49, no. 1, pp. 50-58, Jan. 2013.

[12] I. Scian, D. G. Dorrell, and P. Holik, "Assessment of losses in a brushless doubly-fed reluctance machine," IEEE Trans. Magn., vol. 42, no. 10, pp. 3425-3427, Oct. 2006. 